\title{
Infectious disease in asylums: a fact-finding investigation to prevent tuberculosis contagion in the early twentieth century in Italy
}

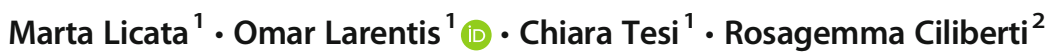 \\ Received: 2 June 2020 / Accepted: 19 September 2020 / Published online: 25 September 2020 \\ (C) Fondazione Società Italiana di Neurologia 2020
}

Nowadays, infectious diseases are a topic of great interest in the scientific community. One of the main issues concerns the spread of infections within hospitals. This is not a new fact. Indeed, doctors and health facilities have always fought against the spread of infections adopting new models, especially during the nineteenth and twentieth centuries. One of the most emblematic infectious diseases in Europe during the last centuries was tuberculosis (TB).

Throughout history, many terms have been used to refer to tuberculosis [1]. Consumption, phthisis, mal du siècle and white plague are some of them. This variety of names is probably due to the difficulties in a proper diagnosis of TB [2]. Indeed, the symptoms of the infection may significantly differ in subjects. Starting from the end of the nineteenth century, thanks to scientific progress, the scientific community was able to understand the disease and, most importantly, to develop an efficient medical treatment.

It is interesting to underline that the treatises on psychiatry of the late nineteenth and early twentieth centuries highlighted the close connection between neuropsychiatric disorders and TB [3]. Indeed, in some scientific articles, some mental

Omar Larentis

olarentis@ uninsubria.it

Marta Licata

marta.licata@uninsubria.it

Chiara Tesi

ch.tesi@gmail.com

Rosagemma Ciliberti

rosellaciliberti@yahoo.it

1 Centre of Research in Osteoarchaeology and Paleopathology, Department of Biotechnologies and Life Sciences, University of Varese, Italy, Varese, Italy

2 Section of Forensic Medicine and Bioethics, Department of Science of Health, University of Genoa, De Toni, 1216132 Genova, Italy alterations diagnosed with TB were indicated as "tuberculous madness".

In particular, in those years, the symptomatology of tuberculosis was well-known and therapies made substantial progress with Forlanini's pneumothorax, while the treatment of mental illnesses was still hinged on substantially ineffective means, to the point that the mental hospital population was always growing in number.

Problematic conditions of asylums such as the scarcity and the decay, the poor hygienic conditions, the overcrowding and the lack of clinical registration are wellknown. In this regard, the complaint by Minister Giovanni Nicotera in an "Inspection on the asylums of the Kingdom" in 1891 is interesting. Indeed, in Italy, medical and political debates were leading the first law on asylums, promulgated in 1904.

Because of the conditions mentioned above, asylums were considered places with a high risk of contracting TB. How did doctors deal with this disease in asylums and what prevention strategies were introduced?

We would like to present an interesting article published in the Rivista Mensile di Psichiatria Forense, Antropologia Criminale e Scienze Affini-Journal of Forensic Psychiatry and Criminal Anthropology-entitled "TB and Madness", signed by Professor A. Grimaldi and by Doctor F. Scotti, psychiatrists of the asylum in Milan [4].

This contribution that represents part of an oral communication at the Congress on TB, which took place in Naples on the 25th-28th of April 1900, encouraged to investigate the connection between mental illness and TB, in order to deal with a situation that was starting to be worrisome: the spread of the disease inside the asylums.

In particular, this investigation was carried out through the following questions: (i) Did TB cause neuropsychiatric alterations? Or (ii) Was mental disease a condition that led to the development of TB? And (iii) Did TB cause, in the progenies of individuals who were affected, a strong predisposition to the mental disease? 
In this article, among the first considerations that the authors reported, it was highlighted that serious signs of neuropsychic degeneration were perpetuated in the families that suffered from TB.

The references to the TB-madness link were also highlighted by other authors of the time, as reported in this article: Baqué affirmed that TB represented one of the causes that determine a general debilitation [5]; Morel argued that situations of poverty and social unease, alcoholism, congenital and acquired diseases were the causes leading to degeneration of the human species and this could be traced back to the Lamarck thought: "all that nature has brought about or lost in individuals through the influence of circumstances, it transmits through the generation to the individuals that derive from it" [6].

The authors reported that the frequency of TB could also affect the health of subsequent generations. Furthermore, the authors affirmed that TB was almost always present in the genealogical trees of the alienated. A. Grimaldi then also referred to his publication where, in the genealogical tree of a paranoid, he highlighted the presence of an ancestor suffering from TB. The authors also underlined that other conditions as syphilis and alcoholism could be associated with neurodegenerative diseases and psychopathological conditions, and also that these conditions were hereditary. These researchers believed that "this occurred because some infectious diseases acted more than others on the nervous system, decreasing the vital energies of the organism and making it unsuitable to transmit to the descendants the power to arrange according to the normal evolutionary rules and the resistance to the various morbid influences".

The authors opened an investigation at the main asylums, health homes and other institutions in Italy by sending a questionnaire with the following inquiries and questions:

1. What was the total number of insane hospitalized in the institute with gender distinction?

2. How many were recognized as suffering from TB in the last five years, and how many improved or healed?

3. How many of them were affected by TB before entering the institute?

4. How many developed TB before or after the beginning of psychopathology?

5. Were there any hereditary precedents of the affected psychiatric patients?

6. How many times TB influenced the symptoms and the course of psychopathology?

7. Did the institute have an infirmary or a special infirmary section for TB?

The investigation showed that in a population of 16,157 alienated, in a five-year period, 937 cases of TB were recorded and among these 802 died. In 71 of 343 cases of TB, the disease occurred before entering the asylum. As for question number four, the authors recorded that many institutes did not respond, even though many were witnessing cases of TB increasing after mental disease. For the fifth question, the difficulty of obtaining the anamnesis of interned subjects and the general lack of information on patients did not provide a significantly readable statistical data.

Having collected the various answers to question number six, the authors supposed that among the symptoms of TB that influenced neuropsychiatric pathology, there were depression, irritability and deterioration of nervous energies. In some cases of TB, however, there were developments and moments of rationality of patients. Finally, regarding the last question, in almost all asylums, there was no separate section for TB.

Finally, the authors pointed out that the number of TB in mental asylums in Italy was significant and the mortality was high.

Many of the psychiatric patients affected by TB contracted the pathology inside asylums. In most cases, TB occurred after psychiatric illness.

Furthermore, the authors identified that the isolation of TB in asylum was not guaranteed and mental illness and the state of the nervous system aggravated during TB, apart from a small number of cases.

The authors were convinced that the inescapable conditions of life inside the asylum, the difficulty of diagnosing TB in the alienated when they entered the institution, the absence of isolation and the crowding of psychiatric structures increased the diffusion of TB.

Indeed, they also reported that the psychiatric patients, not yet recognized as suffering from TB and entering the asylum, spread the disease. Therefore, it happened that those not affected by TB who entered in the asylum to seek treatment for mental illness risked contracting the disease.

The investigation carried out by the authors made it possible to ascertain a very serious condition of contagion in the Italian asylums and hoped for the need for measures.

In particular, they thought of different solutions: (i) that all asylums were equipped with a department for TB and (ii) the foundation of two or three regional sanatoriums, intended to accommodate the mentally ill with TB (Fig. 1).

The problem was already evident, as the proposal to isolate TB affected in asylums was also proclaimed in other countries. As mentioned by authors, in England, psychiatrists planned to build independent sanatoriums to ensure the isolation of patients affected by TB with mental diseases.

The work of A. Grimaldi and F. Scotti is interesting. It was published in 1902, twelve years later, that R. Koch claimed to have discovered the first "remedy" for TB. The end of the nineteenth century was full of hope for a definitive eradication of the disease, and it is undeniable that great strides were made. But, unfortunately, no ultimate solution was found in that period. The diagnosis of TB was a hard challenge for the physicians, and it was with the use of the BCG vaccine in the 
Fig. 1 Project of a sanatorium from the early twentieth century. The main entrance (a) is very far from the rooms for the treatment of infected subjects $(\mathrm{d}, \mathrm{e})$. The connection is only possible thanks to two narrow corridors (b, c). Edited from Grimaldi and Scotti [4]

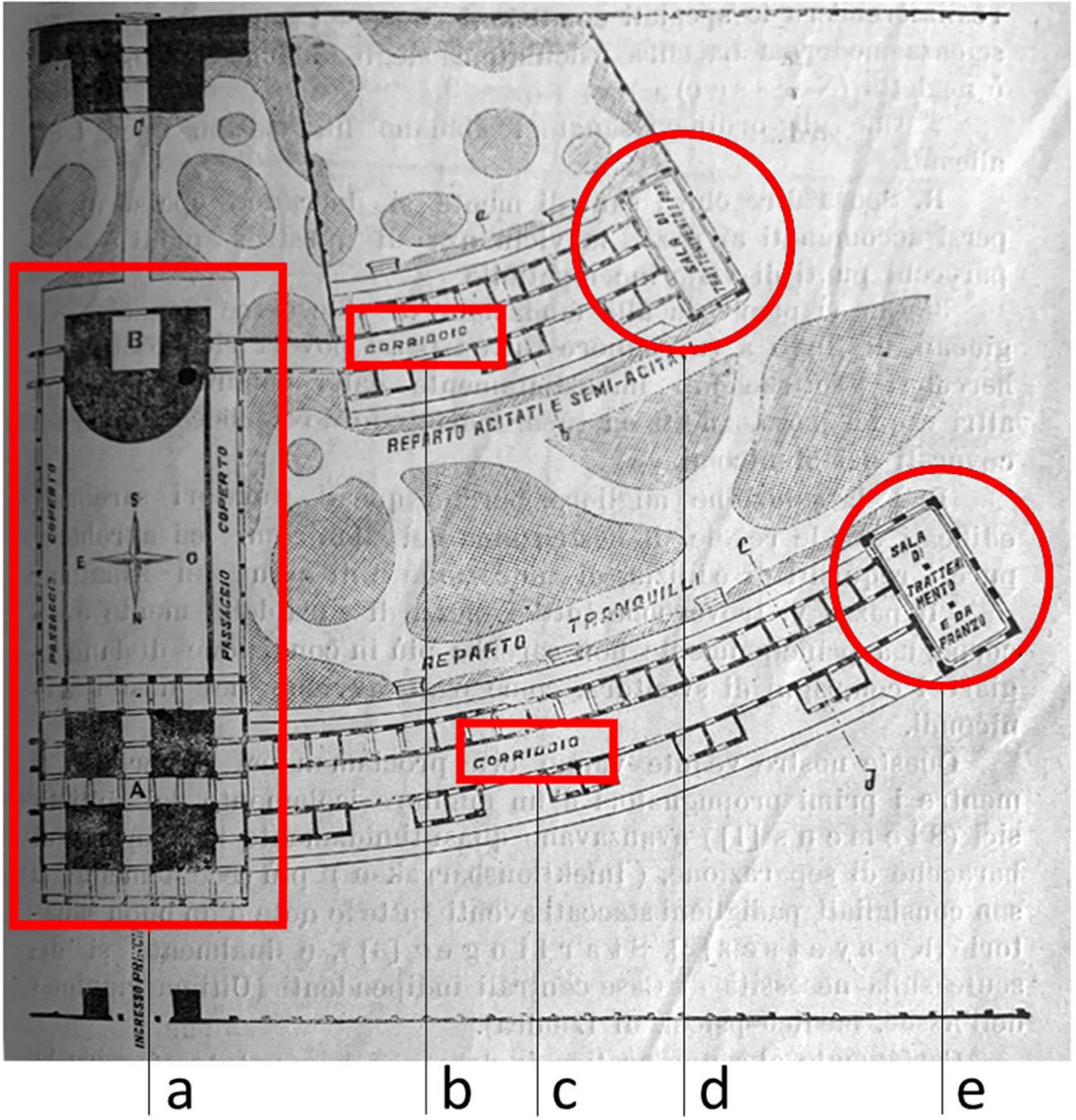

second half of the twentieth century that we can see a real turning point in the battle against the white plague.

It can therefore be thought that the article presented here marked a stage of significant interest especially for those who were engaged in the field of infectious diseases.

The epidemiological investigation that was attempted in psychiatric asylums to understand the contagion of tuberculosis makes us reflect today more than ever and in particular leads to consider that we must always be ready to change our health models to face new challenges of medicine.

It is also necessary to underline that in Italy, tuberculosis has been eradicated by the provision of a network of outpatient centres (anti-tubercular dispensaries), which have developed diagnostic skills and epidemiological expertise, the latter capable of tracing all infections and treating them in an appropriate manner.

In Italy, the first specialized hospital was inaugurated in 1900 in Budrio, a town in the province of Bologna, and it housed 100 beds. The decision to build a sanatorium not in a mountainous area was motivated by the intention to maintain patients in their environment and climate close to the family context. The possibility of maintaining their daily habits and the continuity of family emotional support were considered favourable factors for achieving a more stable "cure". This model of specialized hospital was adopted in Bologna, Gries (Bolzano), Pineta di Sortenna (in the Prealps of Sondrio), Livorno, Rome and Genoa [7].

The sanatorium therapy represented a palliative treatment for symptom control and to stimulate the patient's immune defences through the "air-rest-feeding" triad [8].

In comparison with what is happening today, we can believe that also the suspension of this network and the concentration of acute medical intervention in hospital emergency rooms can be another cause of a rapid spread of coronavirus in Lombardy.

\section{Compliance with ethical standards}

The authors declare that the research did not involve human participants and/or animals 
Conflict of interest The authors declare that they have no conflict of interest.

Ethical approval The authors declare that all procedures performed in studies involving human participants were in accordance with the ethical standards of the institutional and/or national research committee and with the 1964 Helsinki declaration and its later amendments or comparable ethical standards.

Informed consent Informed consent was obtained from all individual participants included in the study.

\section{References}

1. Geddes D (2020) The history of respiratory disease management. Medicine (Abingdon) 48(4):239-243. https://doi.org/10.1016/j. mpmed.2020.01.007

2. Larentis O, Tonina E, Tesi C, Rossetti C, Gorini I, Ciliberti R, Licata M (2020) A probable case of subligamentous tuberculous spondylitis: the concealed body of the Late Modern Period (early 16th century to early 20th century), Franciscan crypt of St. Anthony and St. Eusebius church, Lombardy, Italy. Int J Osteoarch 30(2):180. https://doi.org/10.1002/oa.2845
3. De Domenico P, Musolino R, Di Rosa AE, Serra S, Bonanzinga MM, Gallitto G, Silvestri R, Di Perri R (1988) Tuberculous meningitis: a retrospective survey of 22 cases. Neurol Sci 9:477-482. https://doi.org/10.1007/BF02337166

4. Grimaldi A, Scotti F (1902) Tubercolosi e Pazzia. Rivista Mensile di Psichiatria Forense, Antropologia Criminale e Scienze Affini 5:167174

5. Baqué J (1889) Sur les stigmates physique et les stigmates psysichiques de dégénérescences mental Hérédit. Paris, 1889.

6. Morel BA (1852) Traité des dégénérescences e traité des maladies mentales. Grimblot, Paris

7. Sabbatani S (2005) La nascita dei sanatori e lo sviluppo sociosanitario in Europa ed in Italia. La lotta alla tubercolosi dal periodo post-risorgimentale al 1930. The fight against tuberculosis and developments in public health from 1890 to 1930 in Italy. Le Infezioni in Medicina 2:123-132

8. Del Curto D (2011) La costruzione della rete sanatoriale italiana. In: Il Villaggio Morelli di Sondalo. Identità paesaggistica e patrimonio monumentale, di L. Bonesio and D. Del Curto (Eds.), pp.189-224, Mimesis, Milano.

Publisher's note Springer Nature remains neutral with regard to jurisdictional claims in published maps and institutional affiliations. 